\title{
RESPON ISLAM TERHADAP PERUBAHAN SOSIAL
}

\section{Mohamad Deny Irawan}

Universitas Islam Negeri (UIN) Syarif Hidayatullah Jakarta

Email: hans_deny@yahoo.co.id

\begin{abstract}
As a universal religion, Islam has promised social change in society. Even so, a number of Muslim and Islamic scholars have also admitted that Islam has all the conditions to rise and color the social life of the world community. This article will explain the Islamic response to social change in society, including the role of fatwa as ijtihad products. Religion and Social still get space in the community. At least there are 3 bargaining power positions that are given between religion and society, namely: Religious affairs are more dominant, community affairs are more dominant and compromise between religion and social society in the frame of religion and social frame. This certainly shows that religion as a response to social change as a win-win solution to community life.
\end{abstract}

Sebagai agama universal, Islam telah menjanjikan perubahan sosial di masyarakat. Pun demikian dengan sejumlah cendekiawan muslim serta Islamolog ikut mengakui jika Islam memiliki segala syarat untuk bangkit dan mewarnai kehidupan sosial masyarakat dunia. Artikel ini akan menjelaskan tentang respon Islam terhadap perubahan sosial masyarakat termasuk juga perani fatwa sebagai produk ijtihad. Agama dan Sosial masih mendapatkan ruang di masyarakat. Setidaknya ada 3 posisi daya tawar yang diberikan antara agama dan masyarakat, yaitu: Urusan agama lebih dominan, urusan masyarakat lebih dominan dan kompromi antara agama dan sosial kemasyarakatan dalam bingkai agama maupun bingkai sosial. Hal ini tentunya menunjukan bahwa agama sebagai respon perubahan sosial sebagai win win solution kehidupan bermasyarakat.

Keywords: Ijtihad, Rasionalitas, Radikalisme, Sekularisme, Modernisme

\section{Pendahuluan}

Sebagai agama universal, Islam telah menjanjikan perubahan sosial di masyarakat. Pun demikian dengan sejumlah cendekiawan 
muslim serta Islamolog ikut mengakui jika Islam memiliki segala syarat untuk bangkit dan mewarnai kehidupan sosial masyarakat dunia. John L. Esposito ${ }^{1}$ dalam karyanya yang berjudul rethinking Islam and secularism misalnya, menyebut bahwa pergerakan simbolsimbol Islam, selogan, kelompok serta munculnya aktor penggerak jihad untuk mendobrak ketidakadilan sosial menjadi amat penting dalam proses pergerakan Islam secara umum. Tidak hanya dari segi pergerakan fisik, pergerakan pemikiran juga menjadi perhatian bagi seluruh cendekiawan muslim terkhusus mereka yang bergerak di bidang-bidang praktis seperti fiqh maupun usul fiqh. Yusuf AlQaraḍawi dalam bukunya berjudul Ijtihad mengemukakan urgensi pelaksanaan ijtihad dalam berbagai kesempatan (harakāt aldāimah).² Qaraḍawi menilai bahwa perbedaan pola kehidupan, kompleksitas permasalahan yang muncul hingga perubahan sosial masyarakat yang sedemikian dinamis membuat pelaksanaan ijithad sangat penting dan perlu dilaksanakan meski, beberapa pihak, mempertayakan apakah pintu Ijtihad di masa seperti ini masih terbuka. ${ }^{3}$ Itulah mengapa Islam memposisikan ijithad sebagai sistem perumusan hukum yang sejalan dengan 'umur' Islam di masa-masa mendatang.

Berkaca dari perdebatan antara Wael B. Hallaq dan Josep Schacht tentang kemungkinan terbuka atau tidaknya pintu ijtihad, Ali Khan memberikan pendapatnya. Dalam artikelnya yang berjudul The Reopening of the Islamic Code: The Second era of Ijitihad, Ali

1John L. Esposito, "Rethinking Islam and Secularism" quality data on religion (1998): 1-2

${ }^{2}$ Yusuf Al-Qaraḍawī, Ijtihād Fi Al-Sharīah Al-Islämiyah Ma'a Nadhariyyatu Taḥlìiyyah fi Al-Ijtihād Al-Mu'āṣir (Kuwait: Dāru al-qalam, 1996), 100-101

3Perdebatan soal apakah pintu ijtihad masih terbuka atau tidak terjadi antara Islamolog seperti Josep Schacht dan Wael B. Hallaq. Jika Schact mengatakan bahwa pintu Ijtihad sudah tertutup, maka Wael B. Hallaq menyatakan bahwa pintu Ijithad tidak tertutup. Josep Schacht, Introduction of to Islamic law (Oxford: Oxford University Press, 1982), 70-75. Wael B Hallaq, "On the Origins of the Controversy about the Existence of Mujtahids and the Gate of Ijtihad" Studi Islamica, No.63 (1986) : 130-131. 
Khan mengatakan ada periodesasi pelaksanaan ijtihad. Ali Khan merespon argumentasi sejumlah cendekiawan muslim yang mengatakan tidak semestinya permasalahan-permasalahan yang muncul saat ini diselesaikan dengan solusi-solusi keagamaan yang terlontar di masa lalu. ${ }^{4}$ Sebut saja persoalan ekonomi, politik hingga sejumlah diskursus hukum seperti perbudakan, gender dan diskriminasi keagamaan yang sangat dinamis, sudah tentu, membutuhkan landasan keagamaan yang jelas dan tegas. Ali Khan, selanjutnya, menawarkan era kedua pelaksanaan ijtihad. ${ }^{5}$

Oleh karena itu, makalah ini akan menjelaskan tentang respon Islam terhadap perubahan sosial masyarakat termasuk juga perani fatwa sebagai produk ijtihad.

\section{Ijithad dan perubahan sosial}

\section{Ijtihad sebagai Respon Perubahan}

Secara bahasa, Ijtihad berasal dari kata Ja-Ha-Da yang berarti mengeluarkan kemampuan puncak untuk menghasilkan hukum syari'ah yang berasal dari Al-Qur'an dan hadits dengan metodemetode yang telah berlaku. ${ }^{6}$ Secara spesifik, Wahbab Zuhaili menyebut Ijtihad sebagai proses pengambilan hukum yang bersumber dari dali-dalil yang bersumber dari al-qur'an dan hadits. ${ }^{7}$ Abu Zahroh menambahkan ijtihad sebagai upaya mengeluarkan seluruh potensi kemampuan untuk menjelaskan

${ }^{4}$ Ali Khan "The reopening of the Islamic Code: The Second Era of Ijithad" University of St. Thomas Law Journal vol.1:1 (2003): 342

5 Pada Era kedua Ijithad, metodologi ijtihad dimungkinkan untuk berubah menyesuaikan dengan tempat dan keadaan masyarakat tanpe meinggalkan 2 sumber utama hukum Islam yaitu Al-Qur'an dan Sunnah. Ali Khan "The reopening of the Islamic Code: The Second Era of Ijithad" University of St. Thomas Law Journal vol.1:1 (2003): 384-385

'Yusuf Al-Qaraḍawī, Ijtihād fi Al-Shari'ah Al-Islämiyah Ma'a Nadhariyyatu Tahlilizyyah fi Al-Ijtihāed Al-Mu'āṣir, 11 2,1038

${ }^{7}$ Wahbah Zuhaili, Ușūlu Al-Fiqh Al-Islàmì (Beirut: Dāru al-fikr, 1986) Juz

TAJDID Vol. 17, No. 1, Januari - Juni $2018 \mid 79$ 
hukum dengan segala kekurangan yang dimiliki oleh faqih, produsen produk ijtihad, tentang fenomena hukum di masyarakat.

Ijtihad mensyaratkan beberapa hal bagi pelaksananya, yakni: kemampuan untuk memahami bahasa arab, tafsir al-qur'an, pengetahuan tentang hadits baik sanad ataupun matan, pengetahuan tentang Ijma' para sahabat, täbi'in dan täbi’u al-atbä', memahami qiyas dan mengetahui sebab-sebab hukum hingga proses ditemukannnya sebab hukum (illatu al- hukm). ${ }^{8}$ Ada pula yang menambahkan pemahaman tentang maqūṣid al-sharỉah sebagai syarat lain bagi mujtahid. ${ }^{9}$ Kemampuan-kemampun inilah yang kemudian dijadikan prinsip dasar seseorang yang mengaku sebagai mujtahid.

Dalam Ijitihad, ada dua ranah kehidupan masyarakat (majālu al-ijtihād) yang dapat dibahas, yaitu: ranah ijithad yang boleh dilakukan karena tidak memiliki nas yang jelas dan ada juga ranah ijtihad yang memiliki tidak boleh dilakukan. Contoh ranah ijtihad pertama adalah perintah sholat 5 waktu, puasa, zakat, haji, mengucapkan 2 syahadat, mencuri, minum-minuman keras hingga membunuh. Sedangkan untuk ranah ijtihad kedua yaitu Ijtihad yang dalil-dalinya yang penerapannya bersifat dhanni dan hukumhukum yang belu tercantum dalam al-qu'ran maupun hadits. ${ }^{10}$

Ahmad Raissouni menyebut beberapa kemungkinan atau penjelasan yang terkait persoalan yang bersifat ijtibadiyah seperti: benar-salahnya hasil ijtihad, kebebasan dan pertanggungjawaban

\footnotetext{
${ }^{8}$ Yahya Muhammad, Al-ijtihäd wa al-taqlìd wa al-itibä' wa al-nadhar (Beirut: Al-Intishār al-'arabìy, 2000) , 41

${ }^{9}$ Pertanyaan mendasar dalam syarat ini adalah seputar pemahaman seorang mukallaf tentang pelaksanaan perintah agama. Itulah mengapa, Ahmad Raissouni dan Muhammad Jamāl Bārūt mensyaratkan maqāṣid al-sharīah sebagai salah satu syarat mujtahid. Ahmad al-Raissouni and Muhammad Jamāl Bārūt, Al-Ijtihād: al-naṣ, al-wāqi', al-maṣlạhạh (Beirut: Dāru al-fikr, 2000), 9

${ }^{10}$ Wahbah Zuhaili, Ușülu Al-Fiqh Al-Islàmì, Juz 2, 1052-1053
} 
ijtihad, serta prirotas dalil atau kemaslahatan. ${ }^{11}$ Soal pertama, Raissouni menjelaskn tentang hadits Rasulullah yang mengapresiasi pelaksanaan ijithad meskipun hasilnya tidak tepat. Berikut hadits yang dimaksud Raissouni:

$$
\begin{aligned}
& \text { حدثنا عبد الله بن يزيد المقرئ المكي، حدثنا حيوة بن شريح، حدثني يزيد بن }
\end{aligned}
$$

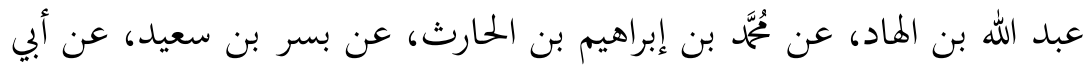

$$
\begin{aligned}
& \text { قيس، مولى عمرو بن العاص، عن عمرو بن العاص، أنه سمع رسول الله صلى }
\end{aligned}
$$

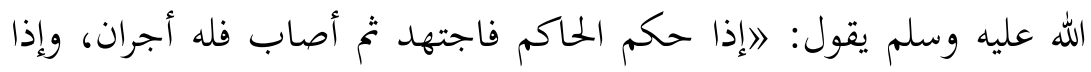

$$
\begin{aligned}
& \text { حكم فاجتهد ثم أخطأ فله أجرها، قال: فحدثت بهذا الحديث أبا بكر بن } \\
& \text { عمرو بن حزم، فقال: هكذا حدثني أبو سلمة بن عبد الرحمن، عن أبي هريرة، }
\end{aligned}
$$

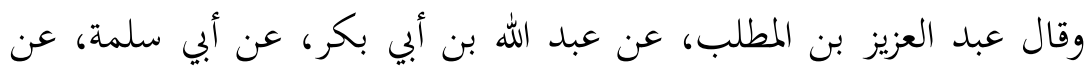

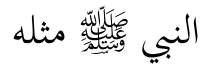

Artinya: Rasulullah Saw bersabda: "Jika seorang hakim memutus acara dengan berjitihad, apabila benar ia dapat 2 pahala, jika ia berijtihad kemudian salah, maka baginya satu pahala." (HR. Bukhari Muslim) $)^{12}$

Dalam hadits ini, Raissouni menggambarkan tentang potensi manusia sebagai seorang mujtahid yang rentan melakukan kesalahan. Menurutnya, ada 3 kemungkinan bagi mujtaahid: pertama, jika ia benar ia mendapatkan 2 pahala; kedua, jika salah ia

${ }^{11}$ Ahmad al-Raissouni and Muhammad Jamāl Bārūt, Al-Ijtihād: al-naṣ, alwāqi', al-mașlahahạ, 12-29

${ }^{12} \mathrm{Abī}$ 'Abdillah Muhammad bin Ismā̄îl al-Bukhārī, Al-Jāmi' al-Ṣahịh (Kairo: Maktabatu Al-Salafiyah, tt) Hadits nomor 7352, Juz 4, 372. Imām AlḤāfidh Abī Al-Husayn Bin Muslim Bin Al-Ḥujaj Al-Qushayrī Al-Naysabūrī, Șaḥih Muslim (Riyadh: Baytu al-afkār al-dawliyah, 1998) Hadits Muslim 1716, 713. 
mendapatkan 1 pahala; dan ketiga, jika salah ia tidak mendapatkan apa-apa. ${ }^{13}$

Sedangkan ijtihad dalam bingkai kebebasan dan pertanggungjawaban diartikan oleh Raissouni sebagai pembatasan atas kebebasan atau improvisasi berlebihan atau kemungkinan menabrak aturan-aturan yang telah ditetapkan. Pasalnya, Ijtihad bagian dari amanat, bahkan dalam beberapa kesempatan ijtihad lebih tinggi dari amanat itu sendiri. ${ }^{14}$

Tidak hanya itu, hubungan antara dalil dan kemaslahatan merupakan dua hal yang tidak dapat dipisahkan satu sama lain. Raissouni membagi 2 ranah maslahat yang dimaksudkan: pertama, ranah permasalahan yang telah jelas dalil, kepastian hukum secara jelas dan terperinci; dan kedua, permasalahan kekinian yang belum ada dalil kusus dalam al-quran dan sunnah. ${ }^{15}$

Dengan beberapa penjelasan diatas, Ijithad dipandang menjadi salah satu model yang ditawarkan oleh Islam sebagai respon terhadap perubahan sosial. Yusuf Al-Qaraḍawi memberikan tiga gambaran ijithad kontemporer, yaitu: Taqnin, Fatwa dan penelitian. ${ }^{16}$ Yusuf Al-Qaraḍawī memberikan kontribusi dalam menunjang pengembangan hukum seperti memberikan motivasi untuk terus menerus menggali hukum Islam dan pengembangannya; memberikan peluang berijithad bagi ulama-ulama; memberikan tuntunan dan pedoman dalam

${ }^{13}$ Ahmad al-Raissouni and Muhammad Jamāl Bārūt, Al-Ijtihād: al-naṣ, alwāqi', al-maṣlaḥah, 12

${ }^{14}$ Ahmad al-Raissouni and Muhammad Jamāl Bārūt, Al-Ijtihād: al-naṣ, alwäqi, al-mașlahah, 15-16

${ }^{15}$ Ahmad al-Raissouni and Muhammad Jamāl Bārūt, Al-Ijtihād: al-naș, alwäqi', al-mașlaḥah, 29

${ }^{16}$ Taqnin yang dimaksud oleh Al-Qaraḍawi adalah ijtihad tidak bertentangan dengan ijithad yang telah dirumuskan para imam madzhab. Yusuf Al-Qaraḍawī, Ijtihād fi Al-Sharīab Al-Islämiyah Ma'a Nadhariyyatu Tahlïliyyah fi AlIjtibād Al-Mu'āṣir, 134

82 | TAJDID Vol. 17, No. 1, Januari - Juni 2018 
berijithad; dan menjawab tantangan zaman di bidang hukum Islam. ${ }^{17}$

\section{Agama dan Sosial: Hubungan Timbal Balik}

Hubungan antara agama dan masyarakat tidak dapat dipisahkan satu sama lain. Bahkan, sinergi keduanya dibutuhkan untuk menjamin kehidupan yang lebih baik. Bambang Pranowo menyebut bahwa masyarakat perlu memahami fenomenafenomena yang terjadi di masyarakat sehingga langkah-langkah untuk mendeskripsikan, membahas, membandingkan serta menganalisis aspek kehidupan sosial-keagamaan dapat dilaksanakan. ${ }^{18}$ Bahkan, Azyumardi Azra menyebut bahwa dalam menganalisa fenomena masyarakat perlu meletakkan posisi manusia sebagai teks yang bisa dibaca. ${ }^{19}$ Dalam konteks agama, posisi manusia sebagai teks inilah yang kemudian dijadikan pedoman dalam mengamati perilaku-perilaku agama di masyarakat.

Salah satu negara yang kondisi sosialnya dipengaruhi agama maupun sebaliknya adalah Nigeria utara. Menurut E. R. Yeld, Islam di Nigeria utara mempengaruhi stratifikasi sosial masyarakat setempat. Dalam penelitiannya, E. R. Yeld meneliti Sokoto, Gwandu, Kano, Katsina dan Zaria dalam yang terangkum dalam suku Fulani-Hausa emirates ${ }^{20}$ dengan kepala suku (the Village Head) merupakan posisi tertinggi di masyarakat seiring dengan superioritas politik yang dimilikinya. Lainnya, posisi pria lebih

${ }^{17}$ Agus Mahfuddin, "Ijithad Kontemprorer Yusuf Al-Qaradawi dalam pengembangan hukum Islam" Religi: Jurnal Studi Islam volume 5, Nomor 1 (2014): 27-41

${ }^{18}$ M. Bambang Pranowo, Memahami Islam Jawa (Jakarta: Pustaka Alvabet, 2011) cet. $2, \mathrm{v}$

${ }^{19}$ Azyumardi Azra dalam kata pengantar buku 'memahami Islam jawa' karya M. Bambang Pranowo. M. Bambang Pranowo, Memahami Islam Jawa (Jakarta: Pustaka Alvabet, 2011) cet. 2, xii-xiv

${ }^{20}$ E. R. Yeld, "Islam and Social Startification in Northern Nigeria" The British Journal of Sociology, vol.11, no. 2 (1960): 114 
tinggi ketimbang wanita serta kehidupan patrilinear yang terhubung 3 generasi. ${ }^{21}$ Sedangkan Islam, secara stratifikasi sosial, berada di posisi paling tinggi diatas kristen dan pagan. hal ini diperkuat dengan superioritas pengikut Mohammedans yang berkembang sejak abad 19 yang terhubung dengan dominiasi tenis Fulani kecuali 3 kepemimpinan yang diemban oleh Hausa. ${ }^{22}$

Selain di Nigeria Utara, perkembangan Pakistan sebagai salah satu negara dengan mayoritas muslim di dunia juga menjadi sorotan, terlebih setelah hadirnya tokoh Abul A'la Al-Mawdūdī yang mengusung pola keadian sosial (Social Justice). Terkait ide alMawdūdi tersebut, Fazlur Rahman menilai bahwa keadilan sosial yang digelorakan tidak lebih dari sekedar upaya melindungi perubahan sisi keIslaman dari versi-versi yang lebih segar (fresh version of Islam); terbangunnya perlawanan yang dinisiasi oleh kalangan Islam yang konservatif yang berdampak pada manuvermanuver politik serta eksploitasi; pekerjaan rumah bagi umat Islam adalah menghubungkan antara moral-moral keIslaman dalam permasalahan ekonomi. ${ }^{23}$ Meski demikian, Muhammad Muslehuddin menilai bahwa peranan Islam di masyarakat dapat pula berbentuk penerapan sistem hukum Islam. Muslehuddin menilai bahwa hukum Islam memiliki kapasitas untuk menjaga rekonsilisasi yang stabil terhadap perubahan. ${ }^{24}$

Sementara itu, India juga mengalami hal serupa. Menurut Nasreen Fazalbhoy, relasi antara muslim-hindu di bidang politik memberikan kekuatan terhadap identitas keagamaan

${ }^{21}$ E. R. Yeld, "Islam and Social Startification in Northern Nigeria" The British Journal of Sociology, vol.11, no. 2 (1960): 115

${ }^{22}$ E. R. Yeld, "Islam and Social Startification in Northern Nigeria" The British Journal of Sociology, vol.11, no. 2 (1960): 115

${ }^{23}$ Fazlur Rahman, "Islam and Sosical Justice" Pakistan Forum, vol. 1, No. 1 (1970):4-5

${ }^{24}$ Muhammad Muslehuddin, "Islamic Law and Social Change" Islamic Studies, Vol.21, No. 1 (1982): 54

84 | TAJDID Vol. 17, No. 1, Januari - Juni 2018 
pemeluknya. ${ }^{25}$ Lebih lanjut, Fazalbhoy mengatakan bahwa muslim di India berusaha untuk selalu belajar dan mengamati fenomena yang tengah menjadi sorotan masyarakat India seperti identitas kelompok, sufisme dan wanita. ${ }^{26}$

Sedangkan di Tunisia, Islam juga memberikan pengaruh sosial yang tidak sedikit terutama yang terkait dengan peran Rachid Ghannouchi dalam menyebarkan Islamisme di Tunisia. Rikke Hostrup Haugbolle dan Fransesco Cavatorta mengatakan bahwa 25 tahun sebelum presiden Ben Ali terpilih, Tunisia menerapkan ekonomi neo-liberal. setelahnya, pergantian sistem ekonomi yang kerap dilaksanakan memuncak kala Tunisia, oleh media prancis $L a$ regente de Charthage yang terbit pada 2009, dianggap sebagai negara mafia. ${ }^{27}$ dalam catatan akhirnya, Rikke Hostrup Haugbolle dan Fransesco Cavatorta mengutip pernyataan seorang psikolog bernama Jerba, pendukung Enhada, yang mengatakan: "You cannot Impose Islam on People. It has to be a personal choice, to com from the heart," (Kau tidak bisa memaksanakan Islam kepada seseorang. Itu adalah pilihan personal yang datangnya dari hati).

Terkait fenomena yang terjadi di Nigeria Utara, Pakistan, India dan Tunisia, dapat kita diambil garis merah bahwa hubungan timbal balik antara Islam dan sosial sangat berpengaruh. Warner J. Chanman mengatakan bahwa perilaku sosial yang terjadi di masyarakat tidak lepas dari kultur budaya ataupun lingkungan sosial yang berkembang di masyarakat. Pun demikian, opsi untuk memisahkan antara kultur budaya atau sosial tidak

${ }^{25}$ Nasreen Fazalbhoy, "Socilogy of Muslims in India" Economic and Political Week.ly, Vol. 32, No. 26 (1997): 1547

${ }^{26}$ Nasreen Fazalbhoy, "Socilogy of Muslims in India" Economic and Political Weekly, Vol. 32, No. 26 (1997): 1549

${ }^{27}$ Rikke Hostrup Haugbolle and Fransesco Cavatorta, "Beyond Ghannouchi: Islamism and Social Cange in Tunisia" Middle East Report, No. 262, Pull of the Possible (2012) : 22 
dimungkinkan. ${ }^{28}$ Bahkan, budaya bisa menjadi salah satu motivasi seseorang untuk bertindak ketimbang hubungan formal yang selama ini disebut sebagai 'hubungan sosial' itu sendiri. ${ }^{29}$

\section{Indonesia: Tarik-ulur Sekulerisme}

Fenomena yang sosial yang terjadi di Indonesia pasca kekalahan Basuki Tjahaja Purnama dalam pemilihan gubernur DKI Jakarta, telah merubah peta sosial masyarakat saat ini. Kalaupun tidak merubah, setidaknya, hubungan antara 2 kelompok agama terbesar di Indonesia, Islam dan Kristen, semakin menunjukkan adu kekuatan masing-masing. Jika komunitas muslim bergerak dengan aksi 212, 411 untuk menuntut gubernur DKI Jakarta dalam kasus penistaan agama yang diikuti dengan kekalahan di Pilkada serta vonis 2 tahun atas kasus penistaan agama, ${ }^{30}$ maka komunitas masyarakat kontra aksi yang dilakukan komunitas muslim menganggap kekalahan Basuki sebagai Pilkada dan vonis 2 tahun adalah sinyal dari tumbuh suburnya sikap anti-kebhinekaan, ${ }^{31}$ intoleransi dan berkembangkanya gerakan-gerakan radikalisme di Indonesia.

Terkait gerakan-gerakan radikalisme di Indonesia, Martin van Bruinessen mengungkapan genealogi kelompok radikal setelah presiden Soeharto lengser dari jabatannya. Menurutnya, ada sejumlah ideologi yang mendasari sikap-sikap radikal sepeti, Sayyid Qutb dan Ali Shari'ati yang menginspirasi gerakan revolusi Islam di Iran. ${ }^{32}$ tidak hanya itu, gerakan-gerakan liberalisme, yang berasal

${ }^{28}$ Werner J. Chanman, "Culture, Civilization, and Social Change" The Sociological Quarterly, Vol. 3, No. 2 (1962): 93

${ }^{29}$ Werner J. Chanman, "Culture, Civilization, and Social Change" The Sociological Quarterly, Vol. 3, No. 2 (1962): 94

30https://www.theguardian.com/world/2017/may/09/jakarta-governorahok-found-guilty-of-blasphemy-jailed-for-two-years

${ }^{31}$ http://news.okezone.com/read/2017/05/07/337/1685202/dinsyamsuddin-siapa-pihak-yang-antikebhinekaan-dan-intoleran

${ }^{32}$ Martin van Bruinessen, "Genealogies of Islamic radicalism in postSuharto Indonesia” South East Asia Research, Vol.10, No. 2 (2002): 149

86 | TAJDID Vol. 17, No. 1, Januari - Juni 2018 
dari barat juga dianggap menginspirasi gerakan-gerakan reformis yang tertanam di pikiran mahasiswa Indonesia yang berada di luar negeri. Martin van Bruinessen menilai pihak-pihak yang terpengaruh oleh Barat terinspirasi deri pemikiran ne-ibnu Rushdian, Hasan Hanafi, Muhammad Abed Al-Jabiri.

Selain radikalisme, sisi positif hubungan antara agama dan interaksi masyarakat di Indonesia tercermin dari sejumlah regulasi pemerintah. Di Indonesia, sejumlah regulasi hukum yang bernuansa Islam terasa seperti UU No.1 tahun 1974 tentang perkawinan, UU Nomor 1/PNPS/1965 tentang Penodaan agama, Kompilasi Hukum Islam, UU Zakat, UU Wakaf, UU Kompilasi Hukum Ekonomi Syariah hingga RUU Penjagaan Umat Beragama dan lain sebagainya.

Mengaitkan dengan kasus Basuki diatas, salah satu dampak sosial atas fenomena tersebut adalah desakan untuk menghapus undang-undang nomor 1/PNPS/1965 tentang penodaan agama. Penistaan/penodaan agama menjadi problem yang terjadi disetiap agama. Dalam hal ini, mempertahankan regulasi tentang penodaan agama mutlak diperlukan hingga, andaikata muncul kelompok masyarakat yang menghendaki penghapusan UU nomor 1/PNPS 1965, adanya perbaikan serta kontekstualitas hukum. ${ }^{33}$

Dalam Islam, perbedaan kelompok serta mazhab tidak digolongkan sebagai perbedaan secara akidah. Hal ini tidak lepas dari tersedianya pilihanmuslim untuk memegang teguh mazhab yang yang dipegangnya. Di Inggris dan Wales, penistaan agama atau sering disebut dengan Blasphemy menjadi salah satu problem yang kerap terjadi sehingga mau tidak mau, perlu diberikan payung hukum untuk melindungi penistaan agama. Menurut Mark hill dan Russel Sandberg, problem penistaan agama menjadi perhatian karena berasal bukan dari penentangan terhadap konvensi eropa

${ }^{33} \mathrm{M}$. Atho' Mudzhar, "Pengaturan kebebasan beragama dan penodaaan agama di Indonesia dan berbagai negara" kajian putusan Mabkamah Konstitusi No.140/PUU-VII/2009 (2010) : 3-4

TAJDID Vol. 17, No. 1, Januari - Juni $2018 \mid 87$ 
tentang Hak Asasi manusia tapi lebih karena bentuk kesesatan dari sekulerisme serta rekaya Sosial yang terjadi. ${ }^{34}$ Kasus pertama terkait penistaan agama terjadi pada Taylor tahun 1676. Taylor mengatakan bahwa jesus adalah seorang bajingan, penipu dan oleh karena itu maka jesus tidak saja melanggar peraturan tuhan dan agama tapi juga telah melanggar hukum, negara dan pemerintah. $4^{35}$ Blasphemy sendiri telah melewati waktu yang panjang dalam sejarah kristen. Talal Asad menyebut kehadiran Blasphemy merupakan konsekuensi dari ajaran kristen yang bebas menyatakan pendapat (freedom of Speech) untuk kepentingan kristen sehingga apapun yang dikatakan kalangan kristen, meski pernyataannya menghina ajaran agama lain, diperbolehkan. $5^{36}$ Dengan beredarnya kasus tersebut, maka tidak heran sebagaimana yang diatur dalam hukum inggris, undang-undang terkait hukuman bagi penista agama diterbitkan pada abad 17. Masih dalam konteks yang sama, Maka perlu juga dibedakan antara kebebasan berpendapat dengan tindakan enistaan atas agama.6

Indonesia, dengan mayoritas masyarakat muslimnya, selalu mengedepankan upaya kerukunan umat beragama. Masyarakat Indonesia, melalu pemerintah selalu mengupayakan cara tentang bagaimana seorang muslim mampu berkomunikasi dengan baik kepada mereka yang non muslim begitu juga sebaliknya. Bahkan tidak jarang, dengan fakta muslim sebagai mayoritas, kaum minoritas terkesan meminta lebih dari apa yang berhak didapatkannya. Menurut Mubarok, Kepala Pusat Kerukunan Umat Beragama Kementrian Agama, kesulitan yang dihadapi lantaran menjalin komunikasi antar umat bergama banyak disebabkan

${ }^{34}$ Mark Hill, Russel Sandberg "Blashpemy and Human Rights: An english Experience in a European Context" : 145

${ }^{35}$ Mark Hill, Russel Sandberg "Blashpemy and Human Rights: An english Experience in a European Context" : 145

${ }^{36}$ Talal Asad, "Free Speech, Blashpemy and Secular Criticisim: Is Critique secular? Blasphemy, Injury and Free Speech" The Towsend papers in the humanities (2009): 34-35. 
persoalan keyakinan yang sifatnya sensitif dan personal. ${ }^{37}$ Namun demikian, bagi Machasin, Staf Ahli Menteri Agama bidang hukum dan HAM, kerukunan umat bergama masih bisa terjalin asalkan menyentuh 3 pokok hal: (1) diferensi perlakuan pejabat daerah dan masyarakat kepada non muslim, (2) minimnya upaya dialog antar agama dan yang terakhir (3) minimnya komunikasi antar umat agama yang dinilai masih renggang. ${ }^{38}$

\section{Penutup}

Agama dan Sosial masih mendapatkan ruang di masyarakat. Setidaknya ada 3 posisi daya tawar yang diberikan antara agama dan masyarakat, yaitu: Urusan agama lebih dominan, urusan masyarakat lebih dominan dan kompromi antara agama dan sosial kemasyarakatan dalam bingkai agama maupun bingkai sosial. Hal ini tentunya menunjukan bahwa agama sebagai respon perubahan sosial sebagai win win solution kehidupan bermasyarakat. Wallähu A'làm bi al-ṣawab

\section{Daftar Pustaka}

Al-Bukhārī, Abī 'Abdillah Muhammad bin Ismāîl. Al-Jāmi' alȘahih (Kairo: Maktabatu Al-Salafiyah, tt)

Al-Naysabūrī, Imām Al-Hāeâdh Abī Al-Husayn Bin Muslim Bin Al-Hujaj Al-Qushayrī. Șaḩịh Muslim (Riyadh: Baytu al-afkār aldawliyah, 1998)

Al-Qaraḍawī, Yusuf. Ijtibād Fi Al-Sharīah Al-Islāmiyab Ma'a Nadhariyyatu Tahlilizyyah fi Al-Ijtihāed Al-Mu'āșir (Kuwait: Dāru al-qalam, 1996)

Al-Raissouni, Ahmad and Muhammad Jamāl Bārūt. Al-Ijtihād: alnaṣ, al-wäai', al-maṣlaḥaḥ (Beirut: Dāru al-fikr, 2000)

37 http://www.republika.co.id/berita/nasional/umum/14/09/20/nc7491tiga-pokok-masalah-dalam-kerukunan-umat-beragama acceced 20 september 2014 Pukul 14.31 WIB

38 http://www.republika.co.id/berita/nasional/umum/14/09/20/nc7491tiga-pokok-masalah-dalam-kerukunan-umat-beragama acceced 20 september 2014 Pukul 14.31 WIB

TAJDID vol. 17, No. 1, Januari - Juni 2018 | 89 
Asad, Talal. "Free Speech, Blashpemy and Secular Criticisim: Is Critique secular? Blasphemy, Injury and Free Speech" The Towsend papers in the bumanities (2009)

Chanman, Werner J."Culture, Civilization, and Social Change" The Sociological Quarterly, Vol. 3, No. 2 (1962)

Esposito, John L. "Rethinking Islam and Secularism" quality data on religion (1998)

Fazalbhoy,Nasreen. "Sociology of Muslims in India" Economic and Political Weekly, Vol. 32, No. 26 (1997):

Hallaq, Wael B. "On the Origins of the Controversy about the Existence of Mujtahids and the Gate of Ijtihad" Studi Islamica, No.63 (1986)

Haugbolle, Rikke Hostrup and Fransesco Cavatorta. "Beyond Ghannouchi: Islamism and Social Cange in Tunisia" Middle East Report, No. 262, Pull of the Possible (2012)

Khan, Ali. "The reopening of the Islamic Code: The Second Era of Ijithad" University of St. Thomas Law Journal vol.1:1 (2003)

Mahfuddin, Agus. "Ijithad Kontemprorer Yusuf Al-Qaradawi dalam pengembangan hukum Islam" Religi: Jurnal Studi Islam volume 5, Nomor 1 (2014)

Mudzhar, M. Atho'. "Pengaturan kebebasan beragama dan penodaaan agama di Indonesia dan berbagai negara" kajian putusan Mabkamah Konstitusi No.140/PUU-VII/2009 (2010)

Muhammad, Yahya. Al-ijtihād wa al-taqlìd wa al-itibä' wa al-nadhar (Beirut: Al-Intishār al-'arabīy, 2000)

Muslehuddin, Muhammad. "Islamic Law and Social Change" Islamic Studies, Vol.21, No. 1 (1982)

Pranowo, M. Bambang. Memahami Islam Jawa (Jakarta: Pustaka Alvabet, 2011) cet. 2

Rahman,Fazlur. "Islam and Sosical Justice" Pakistan Forum, vol. 1, No. 1 (1970)

Schacht, Josep. Introduction of to Islamic law (Oxford: Oxford University Press, 1982)

90 | TAJDID Vol. 17, No. 1, Januari - Juni 2018 